\title{
ANÁLISIS DEL HALLAZGOS GENERALES DEL DESEMPEÑO DE LAS INSTITUCIONES DE LOS CAPÍTULOS DE ASCOLFA
}


Los puntajes promedio de los programas inscritos en capítulos de ASCOLFA muestran tendencia a mejorar y a superar los puntajes globales promedio en todas las pruebas, menos en el módulo de Competencias Ciudadanas. Los capítulos que tienden a mostrar los mejores puntajes promedio son Bogotá, Antioquia y Suroccidente; y los más bajos son Centro, Oriente y Costa Caribe, en todas las pruebas de Saber Pro de 2012 a 2015.

El análisis histórico realizado por cada capítulo de ASCOLFA en las pruebas genéricas nos muestra las siguientes tendencias en sus puntajes promedios ( Tabla 3):

- En Comunicación Escrita la tendencia es descendente hacia ser menor a la media nacional. Esto amerita una revisión en general de este aspecto en todos los programas del área de Administración.

- En Lectura Crítica hay una buena tendencia al ascenso en las puntuaciones, con excepción de los capítulos Centro, Oriente y Caribe, por lo que necesitan mayor apoyo para mejorar este aspecto.

- En Razonamiento Cuantitativo hay buenos promedios que se ubican por encima de la media nacional, pero tienen tendencia a descender en Antioquia, Bogotá y Caribe, donde pueden necesitar apoyo. En este sentido, los capítulos de Oriente y Suroccidente muestran una tendencia ascendente; así, pueden ayudar con su experiencia a apoyar a los que están mostrando tendencias descendentes.

- En Inglés se muestra una tendencia en ascenso y puntajes mayores a la media nacional, especialmente en Caribe. Dado que los puntajes de Inglés se diferencian mucho, este puede ser un patrimonio de formación que está generando el área de Administración, cuya experiencia podría examinarse para extraer lecciones útiles para toda la educación superior colombiana.

- Los capítulos de Bogotá y Antioquia están en el grupo más alto en cuatro de las cinco pruebas, y Suroccidente es el más alto de Razonamiento Cuantitativo, participando generalmente como el tercero con mejores resultados en relación a los demás, lo cual muestra tendencias a mante- 
ner puntuaciones mayores en regiones centrales del país. Sin embargo, Suroccidente y Oriente muestran tendencias ascendentes muy importantes en Razonamiento Cuantitativo e Inglés, que pueden ser de gran interés como experiencias ejemplo para generar apoyos necesarios en educación superior en toda Colombia. Por el contrario, Centro y Caribe siguen ocupando puntajes muy bajos, por lo cual pueden necesitar apoyo muy fuerte en todas las áreas para mejorar el nivel de formación en Administración en dichas regiones.

Tabla 3. Tendencias de desempeño en módulos de competencias genéricas de Saber Pro en instituciones inscritas en ASCOLFA.

\begin{tabular}{|c|c|c|c|c|c|}
\hline $\begin{array}{c}\text { PRUEBAA } \\
\text { CAPITULO }\end{array}$ & $\begin{array}{c}\text { Comunicación } \\
\text { Escrita }\end{array}$ & $\begin{array}{l}\text { Lectura } \\
\text { Crítica }\end{array}$ & $\begin{array}{c}\text { Razonamiento } \\
\text { Cuantitativo }\end{array}$ & Inglés & $\begin{array}{c}\text { Competencias } \\
\text { Ciudadanas }\end{array}$ \\
\hline Bogotá & $\begin{array}{l}\text { Descenso } \\
\text { Menor media } \\
\text { nacional } \\
\text { Mayor en } 2013 \\
\text { Tercero 2012 } \\
\text { Primero } 2013 \text { a } \\
2015\end{array}$ & $\begin{array}{l}\text { Ascenso a } 2015 \\
\text { Grupo mayor } \\
2012 \text { a } 2015 \\
\text { Mayor media } \\
\text { nacional } 2013 \text { a } \\
2015 \\
\text { Menor en } 2012\end{array}$ & $\begin{array}{l}\text { Descenso } \\
\text { Mayor media } \\
\text { nacional } 2012 \text {, } \\
2013 \text { y } 2015 \\
\text { Tercero } 2015\end{array}$ & $\begin{array}{l}\text { Ascenso } \\
2013 \text { a } 2015 \\
\text { Mayor media } \\
\text { nacional } \\
2013 \text { a } 2015 \\
\text { Grupo mayor } \\
2012 \text { a } 2015\end{array}$ & $\begin{array}{l}\text { Igual media } \\
\text { nacional } 2012 \\
\text { Mayor media } \\
\text { nacional } 2015 \\
\text { Primero } 2012 \text { a } \\
2015\end{array}$ \\
\hline Antioquia & $\begin{array}{l}\text { Descenso } \\
\text { Menor media } \\
\text { nacional } \\
\text { Mayor en } 2012 \\
\text { Primero 2012 } \\
\text { Tercero 2015 }\end{array}$ & $\begin{array}{l}\text { Ascenso a } 2015 \\
\text { Grupo mayor } \\
2012 \text { a } 2015 \\
\text { Mayor media } \\
\text { nacional } 2013 \text { a } \\
2015 \\
\text { Menor en } 2012 \\
\end{array}$ & $\begin{array}{l}\text { Descenso } \\
\text { Mayor media } \\
\text { nacional } 2015 \\
\text { Segundo } 2015\end{array}$ & $\begin{array}{l}\text { Ascenso } \\
2013 \text { a } 2015 \\
\text { Mayor media } \\
\text { nacional } \\
2013 \text { a } 2015 \\
\text { Primero } \\
2012 \text { a } 2015 \\
\end{array}$ & $\begin{array}{l}\text { Mayor media } \\
\text { nacional } 2015 \\
\text { Segundo } 2012 \text { a } \\
2015\end{array}$ \\
\hline Suroccidente & $\begin{array}{l}\text { Descenso } 2012 \text { a } \\
2013 \\
\text { Ascenso } 2014 \text { a } \\
2015 \\
\text { Menor media } \\
\text { nacional }\end{array}$ & $\begin{array}{l}\text { Ascenso a } 2015 \\
\text { Grupo mayor } \\
2012 \text { a } 2015 \\
\text { Mayor media } \\
\text { nacional } 2015 \\
\text { Menor en } 2012\end{array}$ & $\begin{array}{l}\text { Ascenso } \\
\text { Mayor media } \\
\text { nacional } 2015 \\
\text { Primero } 2015\end{array}$ & $\begin{array}{l}\text { Descenso } \\
2013 \text { a } 2015 \\
\text { Mayor media } \\
\text { nacional } \\
2013 \text { a } 2015 \\
\text { Grupo mayor } \\
2012 \text { a } 2015\end{array}$ & $\begin{array}{l}\text { Mayor media } \\
\text { nacional } 2015 \\
\text { Tercero } 2012 \text { a } \\
2015\end{array}$ \\
\hline Centro & $\begin{array}{l}\text { Descenso } \\
\text { Menor media } \\
\text { nacional }\end{array}$ & $\begin{array}{l}\text { Ascenso a } 2015 \\
\text { Grupo menor } \\
2012 \text { a } 2015 \\
\text { Mayor media } \\
\text { nacional } 2015 \\
\text { Menor en } 2012\end{array}$ & $\begin{array}{l}\text { Descenso } 2012 \text { a } \\
2014 \\
\text { Menor media } \\
\text { nacional } 2012 \text { a } \\
2014 \\
\text { Grupo menor } \\
2012 \text { a } 2015\end{array}$ & $\begin{array}{l}\text { Ascenso } \\
2013 \text { a } 2015 \\
\text { Mayor media } \\
\text { nacional } \\
2015\end{array}$ & $\begin{array}{l}\text { Grupo menor } \\
2012 \text { a } 2015\end{array}$ \\
\hline
\end{tabular}


RETOS A LOS PROGRAMAS DE ADMINISTRACIÓN. UNA MIRADA AL SABER.

Resultados de la Evaluación Externa (2012-2016)

\begin{tabular}{|c|c|c|c|c|c|}
\hline $\begin{array}{c}\text { PRUEBA } \\
\text { CAPITULO }\end{array}$ & $\begin{array}{c}\text { Comunicación } \\
\text { Escrita }\end{array}$ & $\begin{array}{l}\text { Lectura } \\
\text { Crítica }\end{array}$ & $\begin{array}{c}\text { Razonamiento } \\
\text { Cuantitativo }\end{array}$ & Inglés & $\begin{array}{c}\text { Competencias } \\
\text { Ciudadanas }\end{array}$ \\
\hline Oriente & $\begin{array}{l}\text { Descenso } 2012 \text { a } \\
2013 \\
\text { Ascenso } 2014 \text { a } \\
2015 \\
\text { Menor media } \\
\text { nacional }\end{array}$ & $\begin{array}{l}\text { Ascenso a } 2015 \\
\text { Grupo menor } \\
2012 \text { a } 2015 \\
\text { Mayor media } \\
\text { nacional } 2015 \\
\text { Menor en } 2012\end{array}$ & $\begin{array}{l}\text { Ascenso } \\
\text { Menor media } \\
\text { nacional } 2012 \text { a } \\
2014 \\
\text { Grupo menor } \\
2012 \text { a } 2015\end{array}$ & $\begin{array}{l}\text { Ascenso } \\
2013 \text { a } 2015 \\
\text { Mayor media } \\
\text { nacional } \\
2015\end{array}$ & $\begin{array}{l}\text { Grupo menor } \\
2012 \text { a } 2015\end{array}$ \\
\hline Caribe & $\begin{array}{l}\text { Descenso } \\
\text { Menor media } \\
\text { nacional } \\
\text { Sexto } 2012 \text { a } \\
2015\end{array}$ & $\begin{array}{l}\text { Ascenso a } 2015 \\
\text { Grupo menor } \\
2012 \text { a } 2015 \\
\text { Mayor media } \\
\text { nacional } 2015 \\
\text { Menor en } 2012\end{array}$ & $\begin{array}{l}\text { Descenso } 2012 \text { a } \\
2014 \\
\text { Menor media } \\
\text { nacional } 2012 \text { a } \\
2014 \\
\text { Grupo menor } \\
2012 \text { a } 2015\end{array}$ & $\begin{array}{l}\text { Ascenso } \\
2013 \text { a } 2015 \\
\text { Mayor media } \\
\text { nacional } \\
2013 \text { a } 2015\end{array}$ & $\begin{array}{l}\text { Grupo menor } \\
2012 \text { a } 2015 \\
\text { Sexto } 2012 \text { a } \\
2015\end{array}$ \\
\hline
\end{tabular}

Fuente: elaboración de los autores. 